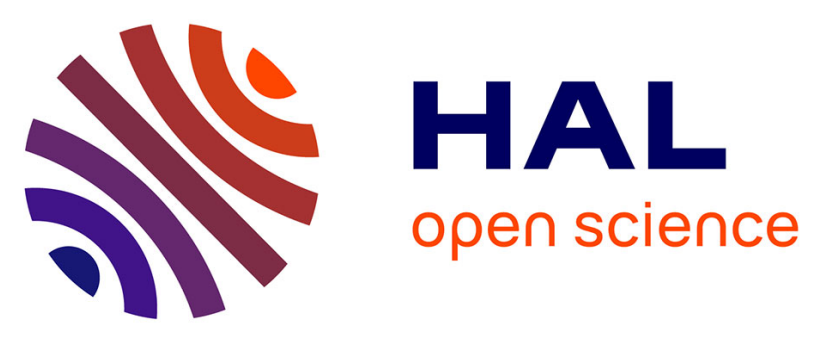

\title{
The Simulation Training in Coronary Angiography and Its Impact on Real Life Conduct in the Catheterization Laboratory
}

Batric Popovic, Samuel Pinelli, Eliane Albuisson, Pierre Adrien Metzdorf, Brice Mourer, Nguyen Tran, Edoardo Camenzind

\section{To cite this version:}

Batric Popovic, Samuel Pinelli, Eliane Albuisson, Pierre Adrien Metzdorf, Brice Mourer, et al.. The Simulation Training in Coronary Angiography and Its Impact on Real Life Conduct in the Catheterization Laboratory. American Journal of Cardiology, 2019, 123, pp.1208-1213. 10.1016/j.amjcard.2019.01.032 . hal-03486633

\section{HAL Id: hal-03486633 \\ https://hal.science/hal-03486633}

Submitted on 20 Dec 2021

HAL is a multi-disciplinary open access archive for the deposit and dissemination of scientific research documents, whether they are published or not. The documents may come from teaching and research institutions in France or abroad, or from public or private research centers.
L'archive ouverte pluridisciplinaire HAL, est destinée au dépôt et à la diffusion de documents scientifiques de niveau recherche, publiés ou non, émanant des établissements d'enseignement et de recherche français ou étrangers, des laboratoires publics ou privés.

\section{()ㅜ(1)}

Distributed under a Creative Commons Attribution - NonCommerciall 4.0 International 
Version of Record: https://www.sciencedirect.com/science/article/pii/S0002914919301249

Manuscript_50af9560d3622f223d80cb838339ae57

The Simulation Training in Coronary Angiography and its Impact on Real Life Conduct in the

Catheterization Laboratory.

\section{Simulation Training in Coronary Angiography}

Batric Popovic ${ }^{\text {a }}, \mathrm{MD}, \mathrm{PhD}$, Samuel Pinelli ${ }^{\mathrm{a}}, \mathrm{MD}$, Eliane Albuisson ${ }^{\mathrm{b}}, \mathrm{MD}, \mathrm{PhD}$, Pierre Adrien Metzdorf ${ }^{\mathrm{a}}$, MD, Brice Mourer ${ }^{c}$, Nguyen $\operatorname{Tran}^{\mathrm{c}} \mathrm{PhD}$, Edoardo Camenzind ${ }^{\mathrm{a}}$, MD

\footnotetext{
${ }^{a}$ Université de Lorraine, Faculté de Médecine, Vandoeuvre-lès-Nancy, France; CHRU de Nancy, Département de cardiologie, Hôpital de Brabois, Vandoeuvre-lès-Nancy, France

${ }^{\text {b }}$ Université de Lorraine, Faculté de Médecine, Vandoeuvre-lès-Nancy, France; CHRU de Nancy, Plateforme d'aide à la recherche clinique (PARC-UMDS), Hôpital de Brabois, Vandoeuvre-lès-Nancy, France

${ }^{c}$ Université de Lorraine, Faculté de Médecine, InSciDense, Vandoeuvre-lès-Nancy, France; Ecole de Chirurgie, Faculté de médecine, Vandoeuvre-lès-Nancy, France
}

Address:

Département de cardiologie, Hôpital de Brabois, Vandoeuvre-lès-Nancy, France

* Corresponding author: Tel: (33) 38-315-3232; fax: (33) 38-315-4226.

E-mail address: b.popovic@ chu-nancy.fr

Declarations of interest: none

(C) 2019 published by Elsevier. This manuscript is made available under the CC BY NC user license https://creativecommons.org/licenses/by-nc/4.0/ 


\section{Abstract}

Our study aimed to evaluate the effectiveness of mentored simulation training (ST) in coronary angiography and to assess the transferability of acquired skills from virtual reality to the real world. Twenty cardiology residents were randomized to ST or control before performing real-life cases in the catheterization laboratory. The control group underwent secondary ST and re-performed real-life cases in the catheterization laboratory. Skill metrics were compared between the ST and the control group, and within the control group between before and after ST. In real-life cases, the procedure time was shorter $(\mathrm{p}=0.002)$, the radiation dose lower $(\mathrm{p}=0.001)$, and the global procedure skill score was higher $(\mathrm{p}=0.0001)$ in the ST group as compared to the control (before ST) group. During virtual ST procedural time $(\mathrm{p}<0.001)$, fluoroscopic time $(\mathrm{p}<0.001)$, training contrast amount $(\mathrm{p}<0.001)$, and global training score $(\mathrm{p}<0.001)$ significantly decreased. In the control group, all monitoring procedure parameters were significantly improved after ST, as well as, the global procedure flow score $(\mathrm{p}<0.0001)$. In conclusion, simulator-based training in coronary angiography improved operator skills compared to traditional in catheterization laboratory mentor-based training. ST should be incorporated in the curriculum of the interventionalist to improve learning in coronary angiography.

Key words: coronary artery disease, coronary angiography, simulation, training, education 
Introduction

The most common approach to training that has been used for decades in many medical disciplines and cardiovascular interventions especially is based "on the job training" on patients. ${ }^{1}$ This apprenticeship model has been largely based on progressive responsibility in the cardiac catheterization (CC) laboratory while performing real procedures on patients under the tutelage of an experienced physician. ${ }^{2,3}$ However, it has become increasingly evident that the CC laboratory should no longer be used as the primary training environment for the acquisition of basic procedural skills. The CC laboratory may not be the ideal educational environment, leading to increased procedural time and trainee stress. Moreover this approach is not standardized and it can result in inconsistent skill acquisition with decreased efficiency. ${ }^{4,5}$

Medical education and procedural training are now evolving using new teaching tools such as online training and virtual reality simulation to train physicians. Medical educators are realizing that time-based and procedurebased certifications are insufficient and that more rigorous methods are required to certify individuals as competent to perform first invasive procedures. ${ }^{6-9}$

Thus, the aim of this pilot study was to evaluate the effectiveness of mentored simulator training on skills acquisition and to assess the transferability of skills from a simulated environment to the CC laboratory.

\section{Methods}

All participants included in our study received didactic teaching in the form of a lecture on the tools most commonly used to perform coronary catheterization and the stepwise sequencing of the procedure.

Participants were instructed on how to perform each step of the procedure and what to pay attention to regarding safety in catheter handling, radiation exposure, and contrast administration. Technical issues regarding catheter shapes and manipulation, table and C-arm handling were explained and demonstrated to the trainees. Prior to perform CA on patients, all participants were instructed to participate in at least 5 CAs performed by an experienced operator in the same teaching hospital to understand how to dress and act in the CC laboratory. Participants were then randomized using the sealed envelope method to receive either a mentored coronary simulation training $(n=10)$ or not $(n=10$; control group) before performing coronary angiographies $(C A)$ on 
patients. The first group underwent virtual training and then performed 4 consecutive coronary procedures on patients in the CC laboratory. The second group (control group) performed 4 consecutive coronary angiographies on patients in the $\mathrm{CC}$ laboratory and were supervised by two experience physicians. Thereafter, the trainees included in this second group underwent virtual training and were reevaluated in further 4 consecutive coronary procedures. (Figure1) These consecutive CAs on real patients were performed by each participant with two supervisors who were instructed to provide oral advice to the trainee if there was a doubt on how to proceed or a sign of a potentially harmful behavior for the patient. Only the procedural steps trainable on the simulator were performed by all the participants. Excluded parts were arterial puncture and flushing of the catheters since these steps were not included in the virtual practice.

Participants were introduced to the Simbionix AngioMentor ${ }^{\mathrm{TM}}$ (Simbionix USA, Cleveland, Ohio, USA). None of them had a previous exposure simulator-based training. The AngioMentor ${ }^{\mathrm{TM}}$ uses catheters and wires that are introduced through a port, allowing the simulator to capture in real-time the movements of both wire and catheter in a two-dimensional space. Visual angle manipulations simulated the typical C-arm movements, along with on-line fluoroscopic images monitored on an adjacent screen.

After completing a brief step-by-step tutorial to familiarize themselves with the technical features of the simulator, each participant performed a full diagnostic catheterization procedure on the simulator. Each participant had to complete five diagnostic AngioMentor ${ }^{\mathrm{TM}}$ simulation procedures showing different culprit coronary artery lesions. During training sessions, angiographies of both the right and left coronary arteries were performed in the standard views for each artery. These procedural reports were then reviewed by the tutor and errors or difficulties were extensively discussed with the trainee.

The simulator training skills checklist included an evaluation of procedural quality (correct cine loops, pressure curve check, correct removal of catheter from the ostium prior to catheter exchange, correct exchange of catheter over the wire, radioprotection procedure, and complication occurrence) and procedural metrics (fluoroscopic time, procedure time, and contrast amount). All the evaluated parameters were summarized in a score (Table 1) The CA skills assessment in patients used a 20-item checklist, including procedural flowchart parameters and procedural metrics. (Table 2)

The design of this study was approved by the institutional review committee According to their nature and distribution, variables are presented as percentage (frequency) for categorical data and mean \pm standard deviation $(\mathrm{SD})$ or median and interquartile range (IQR) for continuous data to perform the statistical analysis of this study. The Student's t test was used for age and because of non-normal distributions, 
others continuous data were compared with the Mann Whitney U test when unpaired and the Wilcoxon signedrank test when paired. For qualitative data, the Chi Square test with, if needed, the Fisher's exact test where used for unpaired and the Mc Nemar's test when paired.

\section{Results}

Twenty participants were included in our study. Participants in both groups were of similar age: and gender (simulation training ST group mean \pm SD, 26.5 $\pm 1,6$ years versus control group 27.6 $\pm 1,8$ years, $\mathrm{p}=0.15$ ) and gender (men in the ST group $n=8(80 \%)$ versus control group $n=5(50 \%), p=0.35)$. All participants practiced on 5 standardized recorded coronary catheterizations on high-fidelity simulators during a 4-hour session. During the training, we observed significantly decreased fluoroscopic time $(\mathrm{p}<0.001)$, procedural time $(\mathrm{p}<0.001)$, and total contrast use amount $(\mathrm{p}<0.001)$, and finally a significant increase in the global training score $(\mathrm{p}<0.001)$ (Figure 2).

The technical performances in 4 consecutive real patients in the ST group versus the control group are presented in Table 3. Compared with the control group, participants in the ST group had better procedural performance: shorter procedural time $(\mathrm{p}=0.002)$ and higher total performance score $(\mathrm{p}=0.0001)$, including higher procedure flow score $(\mathrm{p}=0.006)$ and higher monitoring procedure score $(\mathrm{p}=0.0001)$.

Fluoroscopic time was not significantly different between both groups but radioprotection measures (collimation, distance reduction between tube and patient) were more frequently applied $(\mathrm{p}=0.014)$, and the radiation dose administered during the procedures was significantly lower $(\mathrm{p}=0.001)$ in the ST group. Globally this was summarized in significantly better clinical performance score for the simulation group $(\mathrm{p}<0.0001)$

Each participant in the control group was also evaluated before and after ST (Table 4). The skill performance improved between the two CA sequences. After the simulation training, the procedural time was significantly shorter $(\mathrm{p}<0.0001)$, the contrast amount injected reduced $(\mathrm{p}=0.016)$, and radiation protection measures were more applied in real cases. All monitoring procedure parameters were significantly improved, as well as, the global procedure flow score.

No complications associated with these clinical procedures were noted neither in the CC laboratory nor in the ward and up to hospital discharge. 


\section{Discussion}

The key findings of our study are: (1) our study documented a significant improvement of skills in realworld practice after a simulator-based training (2) for the first time, to our knowledge; we demonstrated the impact of simulator-based training on transference of skills to real life by an intra-operator evaluation in this cardiological field. Preliminary work with simulators in interventional cardiology has revealed that simulationbased education can effectively evaluate the technical and cognitive skills necessary to safely perform CA. ${ }^{10-13}$ Our study extends the documented utility of simulation-based education in several ways. First, we observed a significant improvement in skill with respect to contrast use, procedure time, fluoroscopic time, and global performance score. In our study, procedural skills on simulator were assessed using a training score which consists of 9 single items. These items refer to the handling of the guiding catheters and the evaluation of different metrics parameters including procedural time, contrast used and fluoroscopic parameters. Experienced interventional cardiologists provided immediate and delayed feedback (debriefing) and used these simulators to transfer their knowledge and skills. The importance of feedback in simulator training has been demonstrated in several simulation studies. ${ }^{11,14}$

According to Volker et al, simulation-based education seems to be a useful adjunct throughout fellowship whatever the individual's initial aptitude and this simulation-based training improved skill performances in all students, including for procedural and fluoroscopic use and the initially observed performance difference reduced with the repetition of simulated procedures and interactive process in learning. ${ }^{15}$

In our study, we extended the impact of simulation training to real-world practice. To our knowledge, this is one of the few studies regarding CC skills to show that simulation-based education improves downstream clinical care. ${ }^{16}$ We were not only able to show a significant skill difference between operators according to previous simulation training or not but also, and for the first time, we were able to document improved intra-operator performances in the clinical setting before and after simulator training. Despite the relatively short training time on the simulator, there was a clear benefit when the simulator-based learning was added. The reason for this superiority can be explained by the better understanding of cardiovascular imaging, radiation safety, familiarity with the technique obtained during the simulator training, facilitating automation of key procedural steps when performing the procedure in real life. This might have resulted in increased mental concentration on 
maneuvering catheters and producing accurate cine loops in a safe environment, leading to safer and better procedures.

In our study, the global performance score and the monitoring parameters score were consistently higher after simulation-based training as attested by the results between the simulation-based training group versus the control group, as well as the results in the control group before versus after simulation-based training. The different goals of the safety monitoring list during clinical life coronarography were multiple: (1) make the procedure safer drawing the attention on the pressure curve checking and avoid coronary dissection, (2) prevent nephrotoxicity by reducing contrast amount, and (3) make the operator aware of radioprotection rules.

The use of ionizing radiation during invasive and interventional procedures can adversely impact both the patient and the medical personnel. Measures to reduce exposure can be linked to the catheterization laboratory configuration (such as architectural shielding, protective equipment, changing X-ray system parameters) and to the operator's behavior during the procedure (such as appropriate fluoroscopy use, position adjustment, radiation surveillance, and radiation safety education). ${ }^{17,18}$ Reducing fluoroscopy and cineangiography time reduces the radiation exposure of both the patient and the operator. In current practice, the number of procedures needed to decrease the mean fluoroscopic time is generally high but our study confirms that appropriate operator behavior had an impact on the delivered amount as estimated by the dose area product. Such findings and recommendations highlight the need and importance to teach early by an experienced radiology trained personnel good operating practice, in order to reduce exposure to ionizing radiation, even when wearing protective equipment. However, there are still major difficulties to integrate training simulation in medical education programs, including high costs of simulators, limited access to simulation centers and lack of standardized curriculum incorporating simulation in cardiology. Some of these obstacles may be overcome with formal incorporation into medical education training programs, and development of standardized and validated simulation-based curricula. Further investigations to evaluate the effect on "real world outcomes" are also warranted.

Some limitations in our study should be taken into account. Training case reports and real-life patients were selected by definition which introduces several biases. Trainee tracking and assessment are challenging and the separate effects of the simulation and the educational didactic were not able to be determinate. Although we believe that the communication and teaching skills of the mentor are an integral component of the intervention, the impact of the quality of these skills on the training effect is not easy to measure. Our study reports a single academic center experience and multicenter randomized studies are needed to further confirm these findings. 
Moreover, assessing practical skills is usually associated with some degree of subjectivity: a simultaneous evaluation of training and real-life procedures using different evaluation modalities such as video recording may be useful.

In conclusion, simulation-based education provides a consistent and standardized learning scheme, enhancing trainee learning through deliberate practice without risk to patients. Training in a safe environment, both for the patient and for the trainee, up to a predefined expert performance level to accelerate the learning curve of the trainee, would be of great importance. Furthermore, simulation can be used as an assessment tool by defining a mastery threshold, ensuring all individuals have reached a predefined level of proficiency to allow a safe patient care.

\section{Conflict of interest statement: None}


1. Pickersgill T. The European working time directive for doctors in training. BMJ 2001;323:1266.

2. Jacobs AK, Babb JD, Hirshfeld JW, Jr., Holmes DR, Jr., Society for Cardiovascular A and Interventions. Task force 3: training in diagnostic and interventional cardiac catheterization endorsed by the Society for Cardiovascular Angiography and Interventions. J Am Coll Cardiol 2008;51:355-361.

3. Gallagher AG and Cates CU. Virtual reality training for the operating room and cardiac catheterisation laboratory. Lancet 2004;364:1538-1540.

4. Cates CU and Gallagher AG. The future of simulation technologies for complex cardiovascular procedures. Eur Heart J 2012;33:2127-2134.

5. Babineau TJ, Becker J, Gibbons G, Sentovich S, Hess D, Robertson S and Stone M. The "cost" of operative training for surgical residents. Arch Surg 2004;139:366-369; discussion 369-370.

6. Green SM, Klein AJ, Pancholy S, Rao SV, Steinberg D, Lipner R, Marshall J and Messenger JC. The current state of medical simulation in interventional cardiology: a clinical document from the Society for Cardiovascular Angiography and Intervention's (SCAI) Simulation Committee. Catheter Cardiovasc Interv $2014 ; 83: 37-46$.

7. Holmboe ES, Wang Y, Meehan TP, Tate JP, Ho SY, Starkey KS and Lipner RS. Association between maintenance of certification examination scores and quality of care for medicare beneficiaries. Arch Intern Med 2008;168:1396-1403.

8. Ting HH, Bates ER, Beliveau ME, Drozda JP, Jr., Harold JG, Krumholz HM, Nishimura RA, Oetgen WJ, Sibley JB and Tcheng JE. Update on the American Board of Internal Medicine Maintenance of Certification Program: a report of the American College of Cardiology's Educational Quality Review Board. J Am Coll Cardiol 2014;63:92-100.

9. Dangas GD and Popma JJ. Recertification in interventional cardiology. JACC Cardiovasc Interv 2008;1:332-334.

10. Lipner RS, Messenger JC, Kangilaski R, Baim DS, Holmes DR, Jr., Williams DO and King SB, 3rd. A technical and cognitive skills evaluation of performance in interventional cardiology procedures using medical simulation. Simul Healthc 2010;5:65-74.

11. Bagai A, O'Brien S, Al Lawati H, Goyal P, Ball W, Grantcharov T and Fam N. Mentored simulation training improves procedural skills in cardiac catheterization: a randomized, controlled pilot study. Circ Cardiovasc Interv 2012;5:672-679. 
12. Ericsson KA. An expert-performance perspective of research on medical expertise: the study of clinical performance. Med Educ 2007;41:1124-1130.

13. Jensen UJ, Jensen J, Olivecrona GK, Ahlberg G and Tornvall P. Technical skills assessment in a coronary angiography simulator for construct validation. Simul Healthc 2013;8:324-328.

14. Boyle E, Al-Akash M, Gallagher AG, Traynor O, Hill AD and Neary PC. Optimising surgical training: use of feedback to reduce errors during a simulated surgical procedure. Postgrad Med J 2011;87:524-528.

15. Voelker W, Petri N, Tonissen C, Stork S, Birkemeyer R, Kaiser E and Oberhoff M. Does SimulationBased Training Improve Procedural Skills of Beginners in Interventional Cardiology?--A Stratified Randomized Study. J Interv Cardiol 2016;29:75-82.

16. Jensen UJ, Jensen J, Ahlberg G and Tornvall P. Virtual reality training in coronary angiography and its transfer effect to real-life catheterisation lab. EuroIntervention 2016;11:1503-1510.

17. Christopoulos G, Makke L, Christakopoulos G, Kotsia A, Rangan BV, Roesle M, Haagen D, Kumbhani DJ, Chambers CE, Kapadia S, Mahmud E, Banerjee S and Brilakis ES. Optimizing Radiation Safety in the Cardiac Catheterization Laboratory: A Practical Approach. Catheter Cardiovasc Interv 2016;87:291-301.

18. Agarwal S, Parashar A, Ellis SG, Heupler FA, Jr., Lau E, Tuzcu EM and Kapadia SR. Measures to reduce radiation in a modern cardiac catheterization laboratory. Circ Cardiovasc Interv 2014;7:447-455.

Figure 1. Flowchart of the study

Figure 2. Evolution of performance during simulation training 


\section{top}
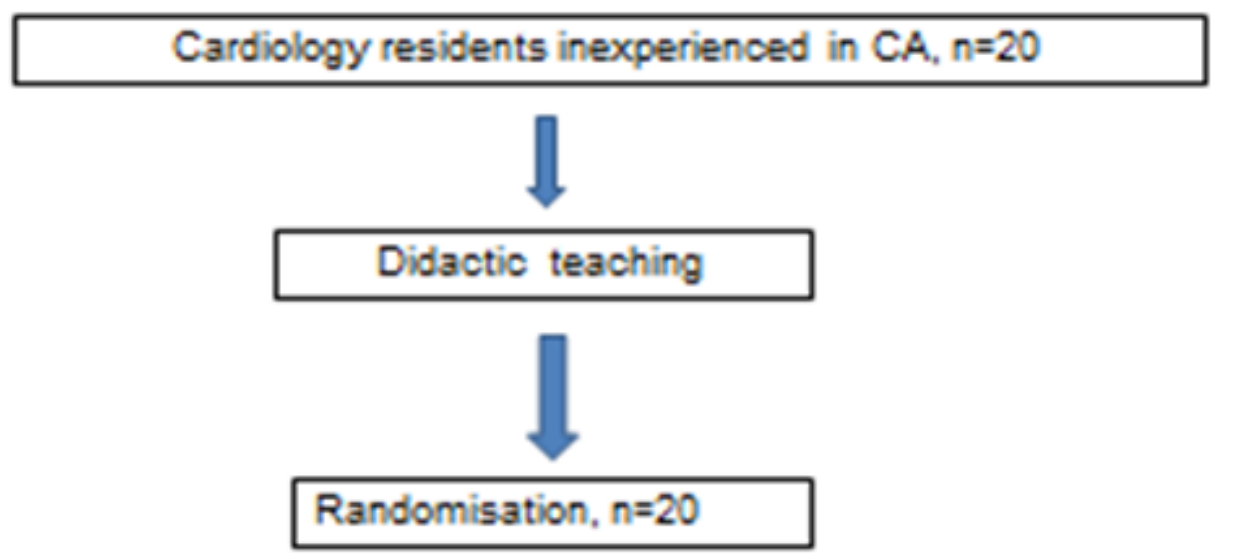

left

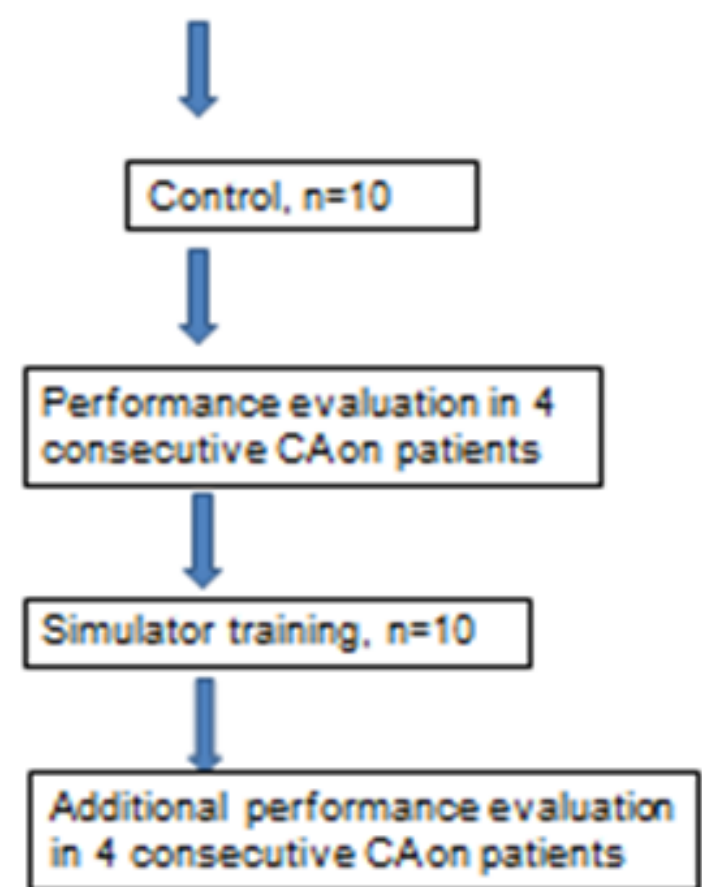

bottom

right

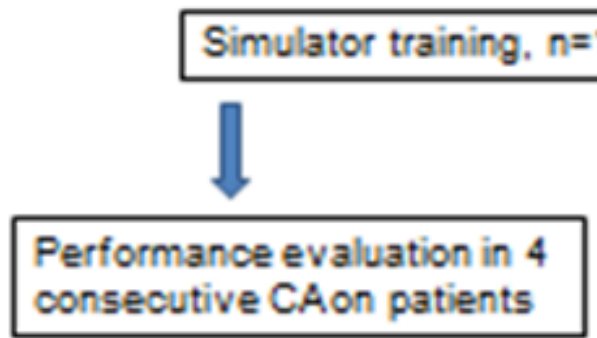

in 4 consecutive CAon patients 
a

procedural time (mn)

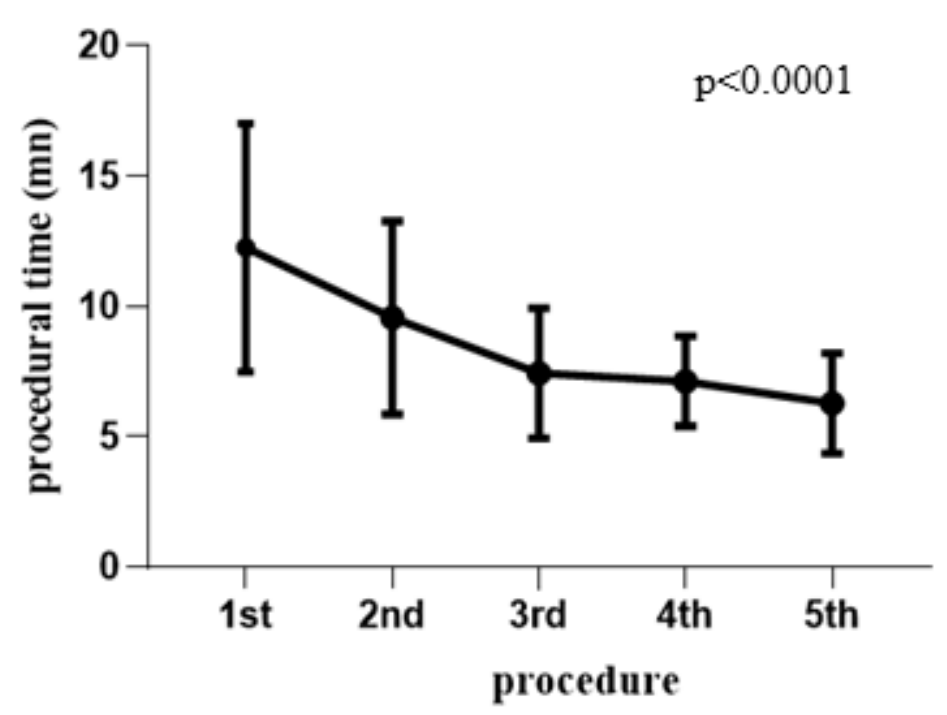

c

contrast use (ml)

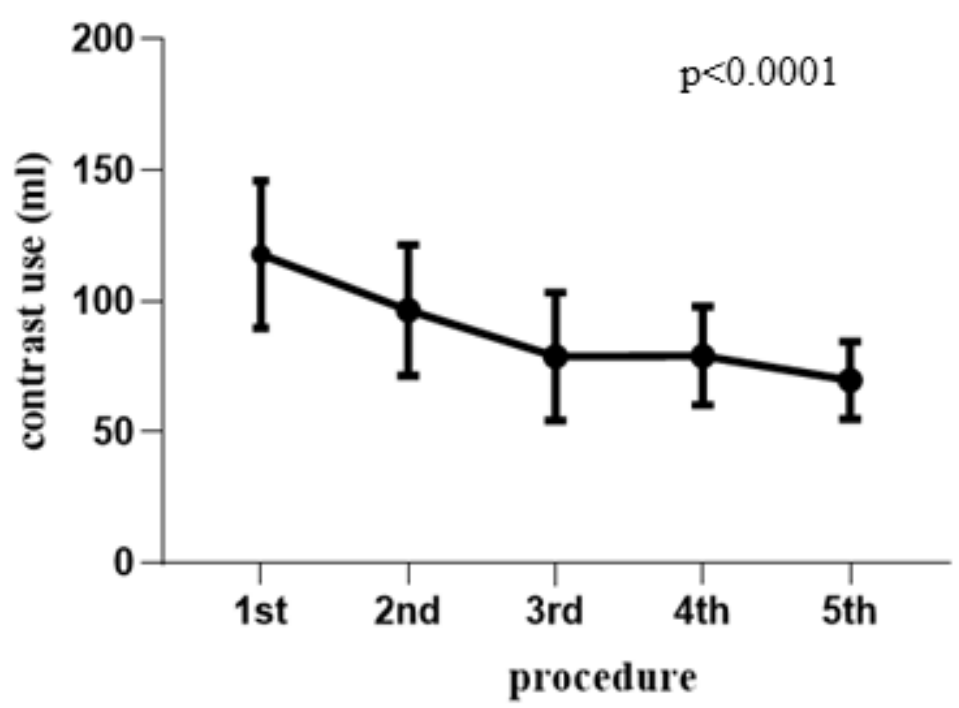

b fluoroscopy time (mn)

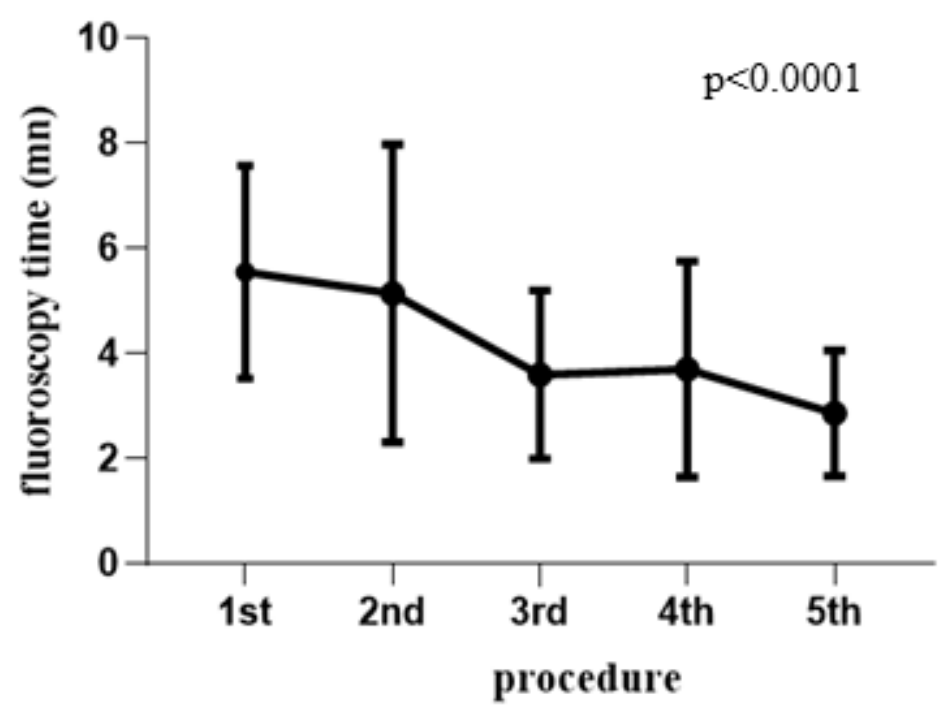

right

d

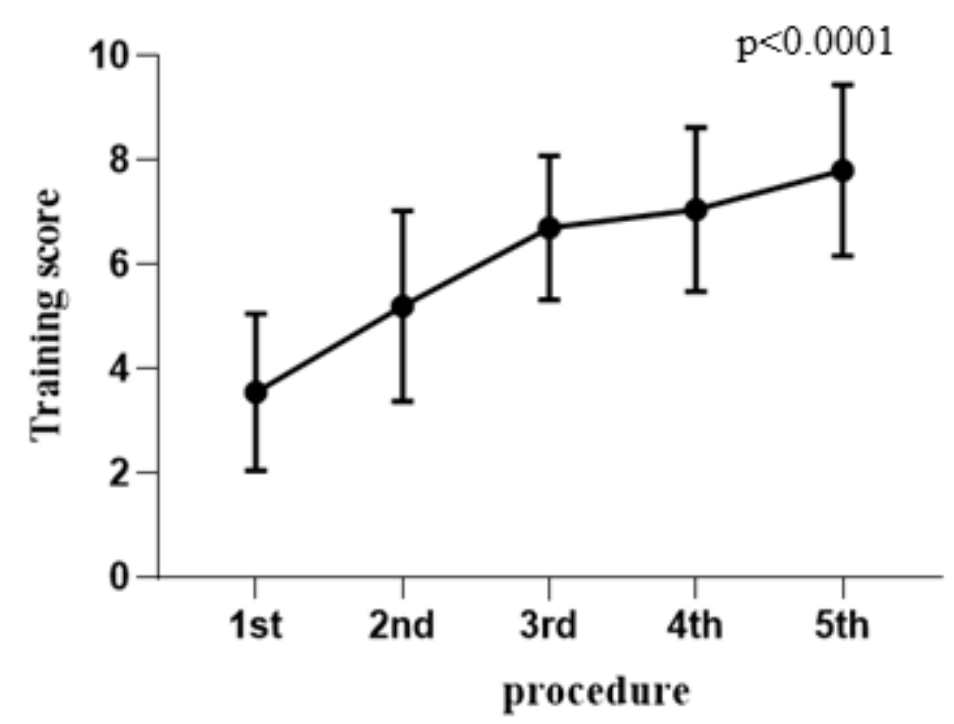

bottom 
Table 1. Simulator parameters evaluated for each case and quantified in a global simulator performance score

\begin{tabular}{ll}
\hline Part 1: Procedural flow & Score \\
\hline Cine loops & 1 \\
Training catheter removal & 1 \\
Training catheter progression and insertion in coronary ostia & 1 \\
Training complications & 1 \\
Subtotal part 1 & $/ 4$ \\
\hline Part 2 : Procedure Quantitative and monitoring parameters & 1 \\
\hline Pressure curves monitoring & 1 \\
Training radioprotection & 1 \\
Training procedural time $<7$ mn & 1 \\
Training fluoroscopy time $<3 \mathrm{mn}$ & 1 \\
Training contrast amount $<100 \mathrm{ml}$ & 15 \\
Subtotal part 2 & 19 \\
\hline Global training score median = subtotal part 1+ part 2 & 1 \\
\hline radioprotection means an appropriate fluoroscopy use and a systematic detector position adjustment during procedures
\end{tabular}


Table 2: clinical parameters evaluated for each patient coronarography and quantified

in a global clinical performance score

\begin{tabular}{ll}
\hline Part 1 : Procedural flow & Score \\
\hline Catheter insertion over wire & 1 \\
Advancement of catheter in aorta & 2 \\
Catheter insertion in Left main & 3 \\
Projections for LM & 1 \\
Projections for LAD and LCX & 1 \\
Catheter removal from LM & 2 \\
Catheter exchange after LM catheterization & 1 \\
Catheter insertion in ostium RCA & 3 \\
Projection for ostium RCA & 1 \\
Catheter removal from RCA & 2 \\
Projection for visualizing RCA & 1 \\
Catheter exchange from RCA & 2 \\
Cineloops number & 1 \\
Subtotal part 1: procedure flow score & $/ 21$ \\
\hline Part 2: Procedure Quantitative and monitoring parameters & \\
\hline Procedure time < 25 mn & 1 \\
Fluoroscopic time < 10 mn & 2 \\
Contrast amount < 100 ml & 2 \\
Radioprotection measures & 2 \\
Drug injections & 2 \\
Pressure curves monitoring & 2 \\
Subtotal part 2: monitoring parameters score & $/ 32$ \\
\hline Global procedure score $=$ Subtotal part 1+part 2 & 2 \\
\hline & 2 \\
\hline Paft & 1 \\
\hline
\end{tabular}

LM: left main LAD: left anterior descending artery LCX: left circumflex artery RCA: right coronary artery coronary. radioprotection measures: an appropriate fluoroscopy use and a systematic detector position adjustment during procedures 
Table 3. Comparison of the clinical performance scores between simulation-based training group (ST) and control group

\begin{tabular}{|c|c|c|c|}
\hline & $\begin{array}{l}\text { Simulation training group } \\
\text { (number of procedures } n=40 \text { ) }\end{array}$ & $\begin{array}{l}\text { Control group } \\
\text { (number of procedures } n=40 \text { ) }\end{array}$ & $\mathrm{P}$ value \\
\hline Catheter insertion over wire & $40(100 \%)$ & $33(83 \%)$ & 0,012 \\
\hline Catheter advancement in aorta & $38(95 \%)$ & $29(73 \%)$ & 0,006 \\
\hline Catheter insertion in LM & $27(68 \%)$ & $40(100 \%)$ & 0,0001 \\
\hline Projections for LM & $40(100 \%)$ & $19(48 \%)$ & 0,0001 \\
\hline Projections for LCA and LCX & $38(95 \%)$ & $36(90 \%)$ & 0,675 \\
\hline Catheter removal from LM & $37(93 \%)$ & $33(83 \%)$ & 0,176 \\
\hline $\begin{array}{l}\text { Catheter exchange after LM } \\
\text { catheterization }\end{array}$ & $36(90 \%)$ & $30(75 \%)$ & 0,077 \\
\hline Catheter insertion in RCA & $31(78 \%)$ & $22(55 \%)$ & 0,033 \\
\hline Projections for ostium RCA & $37(93 \%)$ & $30(75 \%)$ & 0,034 \\
\hline Projections for RCA & $39(98 \%)$ & $37(93 \%)$ & 0,615 \\
\hline Catheter removal from RCA & $40(100 \%)$ & $33(83 \%)$ & 0,012 \\
\hline $\begin{array}{l}\text { Catheter exchange after RCA } \\
\text { catheterization }\end{array}$ & $37(93 \%)$ & $37(93 \%)$ & 1 \\
\hline $\begin{array}{l}\text { Cineloops number } \\
\text { median IQR (IQ1;IQ3) }\end{array}$ & $8(7 ; 9)$ & $7,5(7 ; 8)$ & 0,193 \\
\hline $\begin{array}{l}\text { Procedural time (mn) } \\
\text { median IQR (IQ1;IQ3) }\end{array}$ & $13(10 ; 18)$ & $16(14 ; 18)$ & 0,002 \\
\hline Procedure time $<25 \mathrm{~min}$ & $38(95 \%)$ & $35(88 \%)$ & 0,432 \\
\hline $\begin{array}{l}\text { Fluoroscopic time (mn) } \\
\text { median IQR (IQ1;IQ3) }\end{array}$ & $7(6 ; 8)$ & $8(6 ; 9)$ & 0,221 \\
\hline Fluoroscopic time $<10 \mathrm{mn}$ & $32(80 \%)$ & $32(80 \%)$ & 1 \\
\hline $\begin{array}{l}\text { Contrast amount }(\mathrm{ml}) \\
\text { median IQR }(\mathrm{IQ} 1 ; \mathrm{IQ} 3)\end{array}$ & $87(71 ; 97)$ & $87,5(74 ; 110)$ & 0,361 \\
\hline Contrast amount $<100 \mathrm{ml}$ & $30(75 \%)$ & $24(60 \%)$ & 0,152 \\
\hline Radioprotection measures & $24(60 \%)$ & $13(33 \%)$ & 0,014 \\
\hline $\begin{array}{l}\text { Radiation dose DAP(Gy/cm2) } \\
\text { median IQR (IQ1;IQ3) }\end{array}$ & $2436(1642 ; 38699)$ & $3343(2663 ; 5622)$ & 0,001 \\
\hline Drugs injection & $26(65 \%)$ & $21(53 \%)$ & 0,256 \\
\hline Pressure curves monitoring & $32(80 \%)$ & $1(3 \%)$ & 0,0001 \\
\hline $\begin{array}{l}\text { Procedure flow score } \\
\text { median IQR (IQ1;IQ3) }\end{array}$ & $19(16 ; 21)$ & $17(14 ; 19)$ & 0,006 \\
\hline $\begin{array}{l}\text { Monitoring parameters score } \\
\text { median IQR (IQ1;IQ3) }\end{array}$ & $9(7 ; 11)$ & $5(3 ; 7)$ & 0.0001 \\
\hline $\begin{array}{l}\text { Global Procedure Score } \\
\text { median IQR (IQ1;IQ3) }\end{array}$ & $28(23 ; 30)$ & $22(19 ; 26)$ & 0.0001 \\
\hline
\end{tabular}


Table 4 Comparison of performances in control group before and after secondary simulation training

\begin{tabular}{|c|c|c|c|}
\hline & $\begin{array}{l}\text { Before simulation training } \\
\text { (number of procedures } n=40 \text { ) }\end{array}$ & $\begin{array}{l}\text { After simulation training } \\
\text { (number of procedures } n=40 \text { ) }\end{array}$ & $\mathrm{P}$ value \\
\hline Catheter insertion over wire & $33(83 \%)$ & $39(98 \%)$ & 0.07 \\
\hline Catheter advancement & $29(73 \%)$ & $37(93 \%)$ & 0.039 \\
\hline Catheter insertion in LM & $40(100 \%)$ & $31(78 \%)$ & 0,01 \\
\hline Projections for LM & $19(48 \%)$ & $40(100 \%)$ & 0,001 \\
\hline Projections for LCA and LCX & $36(90 \%)$ & $40(100 \%)$ & 0,20 \\
\hline Catheter removal from LM & $33(83 \%)$ & $38(95 \%)$ & 0.180 \\
\hline $\begin{array}{l}\text { Catheter exchange after left } \\
\text { coronary artery catheterization }\end{array}$ & $30(75 \%)$ & $38(95 \%)$ & 0.039 \\
\hline Catheter insertion in RCA & $22(55 \%)$ & $32(80 \%)$ & 0.052 \\
\hline Projections for ostium RCA & $30(75 \%)$ & $39(98 \%)$ & 0.012 \\
\hline Projections for RCA & $37(93 \%)$ & $40(100 \%)$ & 0,30 \\
\hline Catheter removal from RCA & $33(83 \%)$ & $40(100 \%)$ & 0,05 \\
\hline $\begin{array}{l}\text { Catheter exchange after RCA } \\
\text { catheterization }\end{array}$ & $37(93 \%)$ & $40(100 \%)$ & 0,30 \\
\hline $\begin{array}{l}\text { Cineloops number } \\
\text { median IQR (IQ1;IQ3) }\end{array}$ & $8(7 ; 8)$ & $7(7 ; 9)$ & 0.643 \\
\hline $\begin{array}{l}\text { Procedural time }(\mathrm{mn}) \\
\text { median IQR (IQ1;IQ3) }\end{array}$ & $16(14 ; 18)$ & $9.5(7 ; 11)$ & 0.0001 \\
\hline Procedure time $<25$ min & $35(88 \%)$ & $40(100 \%)$ & 0,10 \\
\hline $\begin{array}{l}\text { Fluoroscopic time }(\mathrm{mn}) \\
\text { median IQR (IQ1;IQ3) }\end{array}$ & $8(6 ; 9)$ & $5(3: 6)$ & 0.001 \\
\hline Fluoroscopic time $<10 \mathrm{mn}$ & $32(80 \%)$ & $36(90 \%)$ & 0,388 \\
\hline $\begin{array}{l}\text { Contrast amount }(\mathrm{ml}) \\
\text { median IQR (IQ1;IQ3) }\end{array}$ & $88(74 ; 110)$ & $79(65 ; 91)$ & 0.016 \\
\hline Contrast amount $<100 \mathrm{ml}$ & $24(60 \%)$ & $34(85 \%)$ & 0.021 \\
\hline Radioprotection measures & $13(33 \%)$ & $31(78 \%)$ & 0.0001 \\
\hline $\begin{array}{l}\text { Radiation dose PDA (cGy/cm2) } \\
\text { median IQR (IQ1;IQ3) }\end{array}$ & $3343(2663 ; 5622)$ & $2309(1323 ; 3488)$ & 0.002 \\
\hline Drugs injection & $21(53 \%)$ & $34(85 \%)$ & 0.0001 \\
\hline Pressure curves monitoring & $1(3 \%)$ & $32(80 \%)$ & 0.0001 \\
\hline $\begin{array}{l}\text { Procedure Flow Score } \\
\text { median IQR (IQ1;IQ3) }\end{array}$ & $17(14 ; 19)$ & $21(18 ; 21)$ & 0.001 \\
\hline $\begin{array}{l}\text { Monitoring parameters score } \\
\text { median IQR (IQ1;IQ3) }\end{array}$ & $5(3 ; 7)$ & $9(9 ; 11)$ & 0.0001 \\
\hline $\begin{array}{l}\text { Global Procedure Score } \\
\text { median IQR (IQ1;IQ3) }\end{array}$ & $22(19 ; 26)$ & $30(27 ; 31)$ & 0.0001 \\
\hline
\end{tabular}

LM: left main; LCA: left circumflex artery; RCA: right coronary artery; DAP: dose area product; IQR: interquartile ratio Radiation procedures: an appropriate fluoroscopy use and a systematic detector position adjustment during procedures 